\title{
WOUND-FIXATION, FOR INTRACAPSULAR EXTRACTION OF CATARACT
}

BY

\author{
ERNEST E. MADDOX
}

BOURNEMOUTH

However satisfied we may be, and I think rightly, with the usual capsulotomy extraction for ordinary mature cataracts, occasions arise when an anti-needling operation is strongly indicated-as, for example, when a sticky, immature lens has a fellow eye previously lost by needling, or by irido-cyclitis accompanying prolonged absorption of cortex, or when a lens is too immature to make ordinary extraction the operation of choice, or when it is tremulous.

The valuable assistance I have received from the following simple expedient, not only in intracapsular extractions, but also

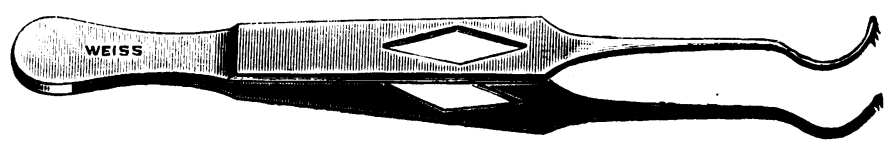

FIG. 1 .

when stone deafness complicates the capsulotomy method, suggests that it may be worth communicating.

It consists, after the completion of a limbal incision, in gripping the extreme cut edge of the conjunctiva in the centre of the upper wound-lip with a fine pair of capsule forceps so curved as to allow easy exit of the lens (Fig. 1). The gentle grip thus secured not only affords excellent control of the eyeball, but counteracts that embarrassing tendency of the cornea to wander up under the lid, which (because it is not a voluntary motion) requires only a very gentle pull to prevent. The instrument, thus holding on to the upper lip of the wound, cannot slip into the eye, or invade the vitreous, yet it enables the upper wound-lip to be depressed and tucked under the emerging lens, and raised again as the equator of the lens passes out so as to bar the vitreous from following.

When the eye needs drawing down this "wound-fixation," as we might call it, has the advantage over the usual lower limbal one of closing the incision, rather than making it gape. With the ordinary capsulotomy operation, it is true, the advantage is trivial, if any; but it becomes of great importance with the larger section, and the feeble protection within the eye against vitreous presentation, characteristic of intracapsulars. This mode of control has, indeed, given me more satisfaction than the traction 
thread, passed through the tendon of the superior rectus, of nearly fourteen years ago (Trans. Ophthal. Soc., U.K., 1914).

I was a little apprehensive at first that the little traumatism of the conjunctival edge by the wound forceps might interfere with the healing of the incision, but that fear proved groundless, for the conjunctiva is so richly supplied with blood that it is extremely tolerant. I have sometimes, it is true, touched the spot with a fine brush moistened with tincture of iodine or with nitrate of silver, but the cases in which this was omitted did just as well. Should the fear of traumatism, however, act as a deterrent, a simple device described below will enable the wound to be avoided.

Almost the only disadvantage arises when we wish to make a long conjunctival flap, for in that case the edge of the conjunctiva is

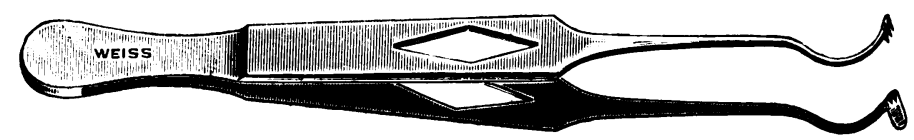

Fig. 2.

too far removed from the wound to be suitable for depression of the upper wound-lip under the lens. To meet this difficulty for which I have not yet had occasion, I have had another pair of forceps made (Fig. 2) with a small thin plate of metal attached to its lower foot, adjacent to the teeth, and standing out at right angles to the handle of the forceps so as to lie in apposition with the bared sclera as far as the upper edge of the wound. By tipping the handle forward, after the conjunctiva has been gripped $2 \mathrm{~mm}$. or $3 \mathrm{~mm}$. away from the wound, the plate can be inclined under the lens, the upper wound-lip being thus depressed as by an inclined plane. Should the fear of traumatism after a limbal incision without a flap make us still wish to keep at a respectful distance from the wound, the tongued forceps can easily be used to grasp the normal conjunctiva higher up, just far enough away to let the blade reach the wound. Should, moreover, any kind of tumbling operation be planned, the tip of the tongue can even lie inside the wound a little to assist in tilting the lens by depression of its upper edge. The figures represent the teeth and tongue as at the extremities of the forceps, but they should really be $2 \mathrm{~mm}$. from the tips. 